Décadrages Décadrages

cinéma, à travers champs Cinéma, à travers champs

$10 \mid 2007$

La trilogie de Dieu de João César Monteiro

\title{
Ecrits choisis de João César Monteiro
}

Traducteur : Ricardo da Silva

\section{(2) OpenEdition}

Journals

Édition électronique

URL : https://journals.openedition.org/decadrages/438

DOI : $10.4000 /$ decadrages. 438

ISSN : 2297-5977

Éditeur

Association Décadrages

Édition imprimée

Date de publication : 10 avril 2007

Pagination : 68-94

ISBN : 978-2-9700582-5-0

ISSN : 2235-7823

Référence électronique

«Ecrits choisis de João César Monteiro », Décadrages [En ligne], 10 | 2007, mis en ligne le 10

décembre 2012, consulté le 03 avril 2022. URL : http://journals.openedition.org/decadrages/438 ;

DOI : https://doi.org/10.4000/decadrages.438

(B) Décadrages 


\section{Ecrits choisis de João César Monteiro}

\section{traduits par Ricardo da Silva}

1 João Bénard da Costa (éd.), João César Monteiro, Edições da Cinemateca, Lisbonne, 2005 Remerciements à João Pedro Monteiro qui nous a gracieusement autorisé à publier les textes qui suivent.
Si l'on devait regarder de manière rétrospective l'ensemble de l'œuvre de João César Monteiro, l'on serait tenté de dire que, d'une manière générale, elle se partage entre le cinéma d'une part et la littérature de l'autre. Une ligne de démarcation nette existerait entre un premier Monteiro, jeune, admirateur des belles lettres, et un second, mature, cinéaste; et dans l'entre-deux, l'on serait passé par une rupture, une crise violente, une révolution. Contrairement à ce point de vue réducteur, nous pouvons soutenir que ces deux intérêts se retrouvent de tout temps dans son auvre, mais selon des optiques différentes. Il n'en demeure pas moins vrai que, d'un point de vue "stratigraphique», il a d'abord connu la vie de bohème, ce qui correspond aux aspirations poétiques de ses vertes années. De retour d'une formation en réalisation à Londres, à une époque de précarité financière, Monteiro a eu recours au journalisme comme moyen de subsistance et a pu, parallèlement, parachever sa formation en tant qu'assistant.

Nous retenons de Monteiro, à travers son auvre cinématographique et les textes publiés de son vivant ou à titre posthume, une certaine forme de continuité qui se retrouve dans la trilogie de Dieu: 1. La création fictionnelle d'un sujet autobiographique, sur le mode picaresque et/ou burlesque, comme dans le recueil poétique Corps submergé, l'article Ma certitude et Le journal intime de Jean de Dieu. 2. L'inscription de sa pratique à l'intérieur de mouvements synchroniques et/ou diachroniques spécifiques au cinéma, comme dans son compte rendu critique Pesaro 70 et la scène inédite Musée du cinéma. Intérieur, jour. 3. L'ancrage socio-politique d'une pratique cinématographique, comme dans Le petit papier.

Les textes ici regroupés ont été traduits à partir du catalogue collectif $\mathbf{1}$ publié par la Cinémathèque portugaise à l'occasion d'une rétrospective de l'œuvre de Monteiro; celui-ci réunit de manière exhaustive les textes écrits par le cinéaste, mais propose aussi un panorama de la critique qui porte sur l'œuvre de Monteiro. Comme le lecteur pourra le remarquer à la lecture des pages suivantes, Monteiro recourt indistinctement à des registres de langage diamétralement opposés, mobilisant aussi bien des expressions populaires communément répandues que des registres littéraires classiques. De plus, les formes syntaxiques qu'il emprunte peuvent parfois, elles aussi, tendre à un maniérisme opaque. Dans cette traduction, nous avons tenté, en se tenant au plus proche de l'original, de 
rendre compte de la dimension transgressive de l'usage de la langue à laquelle Monteiro a recours, tout en ayant à l'esprit la comprébensibilité du texte pour le lecteur francophone.

MA CERTITUDE - Article paru dans le quatrième numéro de la revue \&etc en février 1973 lors de la sortie du film Celui qui

Je suis né le 2 février 1939, à Figueira da Foz.

J'ai eu une enfance capricieuse et bien nourrie au sein d'une famille fortement dominée par l'esprit de la première République ${ }^{1}$, appelons cela ainsi. Il est entendu que les plaisanteries anticléricales abondaient, même si mon père souhaitait que je suive la carrière ecclésiastique. En somme, on n'y comprenait rien. Du moins à première vue.

Autour des 15 ans, je me suis fixé avec ma famille à Lisbonne pour pouvoir poursuivre ma médiocre odyssée lycéenne. Inscrit au collège du $\mathrm{D}^{\mathrm{r}}$ Mario Soares, j’ai été expulsé après avoir contracté une maladie vénérienne dangereuse. J'ai alors pensé qu'entre la politique et la faiblesse de la chair il devait y avoir une quelconque incompatibilité obscène, et depuis lors je n'ai plus jamais été vu en compagnie de politiciens.

Ayant finalement réussi à dissiper toute sa fortune dans la satisfaction d'appétits primaires, mon distingué père est décédé d'une cruelle crise cardiaque en me laissant me gratter la tête, perplexe et sans le sou. Il était temps de donner corps à ce qui était manifeste, comme le font la plupart des gens. Egal à mon père, j’ai traversé en seigneur beaucoup d'emplois variés, mais je me suis rapidement rendu compte que je ne pouvais plus regarder le monde de la même manière. Je suis parti à Paris pour voir s'il m'était possible d'aller plus loin. Des mois plus tard ayant connu pas mal de choses $\mathbf{2}$, j’ai 2 En français dans le texte. été rapatrié.

En 1960, j’ai rencontré M. Seixas Santos qui a eu la bonté de me transmettre une part de ses connaissances du cinéma. $\mathrm{M}$. Vasconcelos était aussi de la partie et paraissait faire des progrès que l'avenir n’a malheureusement (pour lui) pas encore confirmés.

L'année suivante, j’ai travaillé comme assistant réalisateur de M. Perdigão Queiroga, et j’admets que j’aurais pu apprendre deux ou trois choses de plus si je n'avais pas été aussi présomptueux.

En 1963, en tant que boursier illégitimement émérite de la Fondation Calouste Gulbenkian, je suis parti à Londres fréquenter la London School of Film Technique. Je suppose que jamais élève aussi mauvais n'est passé par cette école; je n'ai pas dans ce cas de grands péchés à confesser: en effet, les Anglais ne sont pas nés pour pratiquer le cinéma. En fait, je n’ai pas encore très bien compris pourquoi les Anglais sont nés. Ce doit être pour les mêmes motifs que les punaises, les cafards et le pain complet, le vulgaire pain pétri par le diable, ont vu le jour. Le séjour à Londres 
par contre a été très divertissant, surtout sur le plan salutaire des douces amitiés; toutefois, de retour dans la mère Patrie, mes lamentables acquis scolaires ont été interprétés comme une action honteuse par quelques pleureuses d'enterrement de province; dans ces têtes en pleurs ne passera jamais l'idée que la stupidité et l'incompétence élisent domicile partout dans le monde, y compris au cœur de Londres à la pompeusement nommée London School of Film Technique.

En 1965, j'ai rencontré Paulo Rocha et ses Vertes Années (Verdes Anos), Fernando Lopes et son Belarmino. J'ai noué amitié avec Fernando et je me suis enamouré du film de M. Rocha, que les manies d'anachorète rendaient peu accessible.

Cette même année, j’ai essayé de monter un projet de film en $16 \mathrm{~mm}$ intitulé Celui qui attend après les souliers d'un mort meurt pieds nus (Quem espera por sapatos do defunto morre descalço). Deux jours de tournage et la queue entre les jambes. Sans le sou, j’ai pourtant terminé cette année noire en laissant à moitié achevé le premier film publicitaire qu’on m’a confié ; de même, grâce à un je-ne-sais-quoi, je suis parvenu à éradiquer en trois coups de plume la mauvaise odeur de mes aisselles et à me faire interner dans un hospice pour soulager ma fièvre.

De retour à la vie civile, mes excès ultra-romantiques, tempérés par la profondeur sentimentale la plus noble, ont obtenu enfin une juste consécration (Oh filles de Sidon), ce qui ne m’a pas empêché de tenir un an comme scribe pour Filmes Castello Lopes $\mathrm{Lda}^{3}$.

3 Un des grands producteurs du cinéma portugais du temps de la dictature, et encore actuellement.

En 1968, après une période réconfortante où j’ai découvert qu'il y avait beaucoup de mères mais seulement un père, le céleste, j'ai montré qu'au-delà de l'instinct de conservation, je possédais beaucoup d'autres bons instincts, et j'ai finalement été recommandé au producteur Ricardo Malheiro. Ce fut à ce moment-là, dans l'euphorie la plus déréglée, que j’ai fait le petit film sur Madame Sophie. Peu de temps après, ô disgrâce, Malheiro tombait en faillite ou, ce qui revient au même, la faillite tombait sur Malheiro. Sans grand profit, j’ai encore essayé la publicité. Désespérément. Trois ou quatre films, un voyage, en Guinée (hélas!).

L’année suivante, stimulé par quelques bonnes volontés 4 ,

4 Saudades: expression typiquement portugaise que l'on peut traduire par "doux souvenir teinté de mélancolie".

5 Environ $1500 \mathrm{CHF}$. j’ai décidé de reprendre le projet de Celui qui attend après les souliers d'un mort meurt pieds nus, dont les prises de vue ont traîné durant deux ans. Au moment où le film me sortait par les yeux, la fondation Gulbenkian m'a concédé (merci) un subside de $\$ \$ \$ \$ \$ \$ \$ \$ \$ \ldots 180$ Contos $^{5}$, livrés en trois tranches. A ce moment-là, j'ai eu la tentation de faire un tour. J'ai demandé à Vasconcelos de filmer deux plans qui manquaient au film et je suis parti. L'Italie et l'incontournable Paris. Les finances épuisées, je suis revenu finir le film, recevoir la dernière tranche et repartir, en train ou en stop, selon l'inspiration: Barcelone, Marseille, Florence, Milan, Côme, Cernobbio, Paris.

Entre-temps, le film a commencé par être relativement mal reçu par le mécène (voulait-il une pièce d'opéra pour 180 Contos ?); il a été primé par la suite dans un festival du Sud de l'Espagne et froidement accueilli par la critique à Nice, pendant ladite «Semaine du Jeune Cinéma 
Portugais». Dommage, car cela m'aurait été bien utile, surtout en ce qui concerne l'usufruit de quelques libéralités locales, mais comme cela n'a pas pu être le cas, patience! Hormis cela, j'ai profité du séjour niçois pour acheter un joli costume de bain deux pièces avec le billet de 100 francs que João Bénard $\mathbf{6}$ m’a prêté et j'ai menacé de casser une bouteille de vin rouge sur la tête de

6 João Bénard Da Costa, actuel directeur de la Cinémathèque portugaise et proche de Monteiro. Cunha Telles qui, sans mal y penser, m'a traité d'opportuniste. Je ne suis pas de nature agressive, bien au contraire, mais être insulté par un marchand rusé, c'est quelque chose qui me fait sortir de mes gonds. Je déteste la promiscuité et on m'a appris à garder scrupuleusement mes distances. Pour une simple et unique raison: maintenir intacte et préservée ma personne, au-delà de la conscience de toutes mes erreurs et imperfections. Je prends, la plupart du temps, ce jeu guignolesque avec un sourire en coin, mais ce n'est pas par hasard que de plus en plus de personnes me sont antipathiques.

Les souliers définitivement rangés, j’ai commencé, l'hiver passé, La Sainte Famille (A Sagrada Familia), que j'espère terminer ces prochains jours. Je présume qu'on ne lui réservera pas un meilleur sort qu'à mon film précédent; le cas échéant, qui ne manquera de se produire, cela sera dommageable si ce n'est sur le plan global du cinéma portugais, tout au moins sur le plan particulier de mon propre cinéma, dans l'exacte mesure où d'une part il interroge et corrige dialectiquement le film précédent et d'autre part il prépare déjà le suivant.

Mon prochain film s'appelle La tempête et sera perpétré dans une arrabida $\mathbf{7}$ passée à la peinture Robbialac ${ }^{\mathbf{8}}$ si, comme escompté, les autorités locales ne soulèvent pas d'insurmontables obstacles. Quoi qu'il en soit, il faut rendre hommage aux incommensurables services rendus par l'émérite peinture, qui non seulement arbore les couleurs les plus vives mais encore qui dure le plus longtemps et qui a inspiré les couleurs de la Nation.

Que penser de tout cela? En premier lieu, que la vie va mal pour les pauvres. Et puis, qu'ici ou là, l'on vit tous très occupés, y compris par manque d'occupation. En dernier lieu, et en ce qui me concerne, tant que je passe le temps, comme c'est le cas ici et maintenant, à caresser mon petit ego dilaté et à livrer des images de ma personne raisonnablement alléchantes, comme celles-ci, il y aura des personnes bien plus obscures que moi, qui s'occupent de manière discrète et dévouée de ma personne et de mon glorieux destin, ce qui n'est pas nouveau. Il faut croire qu'il s'agit là d'une constante dans l'Histoire.

$\mathrm{Au}$ vu de la situation, il me faut encore reconnaitre la solitude

7 Arrabida: grande demeure généralement entourée d'une large superficie de terrain. Type d'architecture prestigieuse du Sud du Tage, appartenant généralement à des familles de grands propriétaires fonciers.

8 Marque de peinture peu onéreuse et par conséquent très répandue au Portugal. Monteiro ironise sur les mœurs conservatrices, pro Salazar, des grands propriétaires du Sud. II est à noter qu'à cette époque les milieux ouvriers de cette région sont de plus en plus influencés par la propagande communiste. Lors de la Révolution des œillets, les ouvriers se syndicalisèrent de manière officielle et expulsèrent les propriétaires pour s'organiser de manière collective. Monteiro fait très certainement allusion au climat révolutionnaire en gestation.

9 Référence au fado, musique mélancolique très appréciée des milieux bourgeois pendant la période fasciste. Ce texte a été écrit pendant la dictature, alors que toute référence au fascisme était censurée. La proximité sonore avec neo-fascista est donc délibérée.

morale d'une pratique cinématographique ancrée dans le double refus de me réduire au rôle d'une voiture de location pour la classe exploitante et, ce qui est plus grave, de renoncer à mes exigences profondes en faveur d'une quelconque forme de démagogie néo-fadiste 9 qui véhicule et nourrit la misérable illusion de servir, par procuration abusive, des intérêts qui ne sont pas les siens. 
Série de quatre chroniques sur l'édition du festival de Pesaro de 1970 à laquelle Monteiro avait pris part à titre de — simple spectateur lors de son voyage à travers l'Europe, dont il est question dans l'article Ma certitude. Originellement, ces textes ont été publiés en quatre parties parues à une semaine d'intervalle dans le supplément littéraire du quotidien Diário de Lisboa, entre le 22 octobre et le 19 novembre 1970. A maints égards, ces chroniques introduisent au Portugal ce qui paraît alors constituer un mouvement d'ampleur internationale dans lequel Monteiro tente de se situer.

\section{Pesaro 70/1.}

Du 10 au 17 septembre, a eu lieu à Pesaro la «Sesta Mostra Internazionale del Nuovo Cinema» avec le concours de vingt-trois longs métrages provenant de treize pays: Brésil, Chili, Cuba, Espagne, Etats-Unis, France, Italie, Japon, Nigéria, Pologne, République fédérale allemande, Roumanie et Suède; en outre, quelques (médiocres) courts métrages brésiliens sur le NordOuest et quelques extras qui, comme la majeure partie des productions présentées officiellement, ne justifiaient pas le déplacement (ni le nôtre ni le leur) hors de leur pays d'origine. Ont assisté à cette manifestation cinématographique de l'Adriatique plus de 600 journalistes de la presse quotidienne et spécialisée du monde entier, des représentants d'associations culturelles italiennes, des cinéastes invités (ou non), près de 1000 bouches à nourrir en tout et une demi-douzaine de têtes (ce qui est satisfaisant), bien qu'il y eut un public nombreux qui (justice nous soit rendue) ne se comportait, en général, pas mieux que le nôtre. Les organisateurs ont eu la bonté d'arborer sur la place communale, à côté des drapeaux des pays participants, le drapeau vert et rouge (attention que d'ici nous accueillons patriotiquement avec étonnement et émotion). Ils se sont arrêtés là puisque de nous, décidément, ils n'avaient plus rien à montrer. Du Cinéma Nouveau nous en avons, moi y compris, mais pas de films.

Ceci dit, et avant d'en arriver à une appréciation critique des films auxquels nous accordons notre bénédiction ainsi qu'à quelques conclusions venant contrebalancer le cinéma dit nouveau, en prenant comme référence ce qui nous a été donné de voir à Pesaro, nous commencerons par retranscrire un texte édité dans le catalogue de la Mostra, dans lequel les caractéristiques et les objectifs du cinéma nouveau sont définis, qui nous paraît contenir des éléments utiles et quelques initiatives esquissées (ou à esquisser) dans le contexte cinématographique portugais, même si ces présupposés théoriques ont été trahis à Pesaro dans la majorité des cas par une pratique incorrecte de l'analyse théorique du cinéma, aliénée par une démagogie partisane et révisionniste. Là comme ici, à l'exception de Aprà.

\section{Pesaro 70/2.}

\section{Quelques bonnes raisons}

Nous avions décidé, comme on a pu le lire dans la critique précédente, de ne faire nulle mention des films auxquels nous ne jugeons pas bon d'accorder notre attention. Reste alors à indexer quelques raisons de ce parti pris:

a) Parce qu'il s'agit de films extrêmement académiques dans le sens où leurs structures narratives s'inspirent, ou sont dictées par les idéologies des systèmes suivants: production typique 
de série B hollywoodienne (The Honeymoon Killers de Leonard Karsle), conflit bourgeois avec ses petits soucis conformistes dans la cristallisation de la "révolution inachevée» (Struktura Krystzalu du Polonais Krysztof Zanussi), et ce dans le meilleur des cas.

b) Plus gravement, parce qu'ils substituent à l'analyse d'une problématique sociale une subjectivité sentimentaloïde de premier degré, comme c'est le cas du Roumain Lucian Pitilie dans Reconstituirea, ou comme c'est le cas de Camarades de Marin Karmitz (Fr.), qui manifeste un pseudo-esthétisme à la Lelouch.

c) Parce qu'ils constituent une idiotie galopante évidente. Ex.: Misshandlingen de Lasse Forsberg (Suède); ou un sous-développement offensif du cinéma par rapport au sujet visé. Ex. : El Chacal de Nabueltoro de Miguel Littin (Chili).

d) Parce qu'ils constituent des tentatives peu réfléchies (i.e. ignorant Rossellini et Godard) de dépassement du premier néoréalisme, n'ajoutant rien de nouveau au débat entre le cinéma et le réel. Ex. : Le Parole a Venize de Peter del Monte (Italie).

e) Parce qu'ils réduisent les recherches les plus importantes du cinéma moderne à une caricature dangereuse et confusionniste de celui-ci, que ce soit dans l'adoption précipitée de certaines techniques (plan d'ensemble fixe, déclamation distancée et théâtrale des acteurs, destruction de la narration traditionnelle, etc.) ou dans le recours à des éléments poétiques ou politiques (ou les deux) comme formes discursives. Ex. : Necropolis de Franco Brocani (Italie) et Cabezas Cortadas de Glauber Rocha (Espagne-Brésil), que nous analyserons par la suite.

f) Il faudrait prendre en considération deux expériences intéressantes de cinéma direct: Tercer Mundo Tercera Guerra Mundial, un documentaire du Cubain Julio García Espinosa sur la guerre arrêtée par la RDV contre l'agression impérialiste des USA et, surtout, Partisan Zenshi de Noriaki Tsuchimoto (Japon), portant sur l'agitation universitaire menée à terme par le Zenkyoto, sa théorie et sa pratique adéquate en lien avec le Minsei (secteur ouvrier), hormis ses fonctions dans le domaine universitaire et dans le domaine plus vaste de la politique japonaise. Ici, notre parcimonie est due à des raisons entièrement extérieures aux films, à une incapacité à les situer sur le plan concret des luttes politiques qui constituent leur objet.

g) Finalement, pour n'être arrivé à Pesaro que lors de la deuxième journée de la Mostra, je n'ai pas pu voir Yan-Diga de Serge-Henri Moati (Nigeria-France), ni Come te Chiami Amore moi? de Umberto Silva (Italie). Par distraction, j’ai aussi manqué Seize the Time de Antonello Branca (Italie) et Wie ich ein Negar wurde de R. Gall. On me dit que je n'ai pas perdu grand-chose.

\section{Cabezas cortadas}

Le dernier film du Brésilien Glauber Rocha, tourné en Espagne, a été choisi pour clore la "Sesta Mostra de Pesaro", porteur des plus grandes attentes ${ }^{1}$. Décidément nos collègues brésiliens sont en vogue et la curiosité envers tout ce qui a un parfum brésilien est grande, qu'il s'agisse des chansons de Gilberto Gil, de Caetano Veloso ou encore d'un petit quelque chose du Cinema Nóvo. Glauber, surtout, est très en vue. En ce qui me concerne, étant donné que j’ai peu voyagé, je fais partie des fans ${ }^{2}$, je me

1 Expectativa signifie "attentes les plus positives" mais aussi "spéculations".

2 Torcida signifie "groupe de fans dont l'intérêt témoigné pour un objet est démesuré, irréfléchi, inconditionnel". 
laisse porter par les accords, je rêve du Mato Grosso, et je m'indigne avec le Nord-Ouest. Quant au cinéma, j’avais eu l'opportunité de voir (à Lisbonne) O Menino de Engenho de Walter Lima Jr. Et maintenant, à Pesaro, en marge de la Mostra, j'ai vu un long métrage parfois divertissant, mais bien inférieur d'André Luiz Oliveira, intitulé Meteorango Kid, Heroi intergalactico, et une demidouzaine de documentaires de peu ou d'aucune valeur. De Glauber Rocha, je disposais, et je dispose encore, des meilleures références de la part de la critique européenne, de collègues brésiliens, et de personnes qui parfois vont jusqu'à Paris ou Madrid. Récemment encore Antonio-Pedro Vasconcelos écrivait de Venise les plus flatteuses louanges sur Der Leone Have Sept Cabezas qui précède immédiatement le décevant Cabezas Cortadas. Glauber nous dit et je souscris : «le cinéma a aujourd'hui le choix entre deux solutions : soit faire des films pour divertir les masses, en recourant à une technique académique; soit faire des films de polémique sociale, en cherchant de nouvelles formes d'expression. Cabezas Cortadas est un exemple du second cas». Sur ce point, si j'étais Glauber, je ne serais pas aussi sûr de moi. L'expression «divertir les masses» ne répond pas aux mêmes paramètres dans un contexte européen que, par exemple, dans un contexte sud-américain. Il suffirait d'analyser l'évolution de la production cinématographique européenne destinée à la consommation européenne pour rapidement avoir la preuve qu'elle obéit à de nouvelles exigences qui, de manière exemplaire, ne se déprennent en aucune façon des façades de styles faussement modernes et de certaines préoccupations culturelles, sociales et politiques.

Selon Glauber, Cabezas Cortadas "n'est pas un film pourvu d'une syntaxe traditionnelle... c'est un film qui se situe entre le théâtre et la poésie». Plus loin:

"C'est un film qui cherche à entrer en communication avec la sensibilité du spectateur, en utilisant un langage différent du cinéma traditionnel. Ainsi le spectateur doit accepter le film comme s'il lisait un poème, comme s'il écoutait de la musique ou regardait une exposition de peinture... Cabezas Cortadas peut être défini comme un film surréaliste, mais peut aussi être considéré comme une fable...

... En conclusion, je ne peux pas considérer Cabezas Cortadas comme un film authentiquement espagnol... C'est un film qui repose sur la seule réalité du Tiers-Monde comme source d'inspiration de ses images, de ses sons et des personnages qui sont montrés pendant une heure et demie de projection.»

Quant à moi, en faisant preuve de bonne volonté, il me semble que Rocha a été affecté par une forme de mimétisme culturel ou par ce que Pessoa, prosaïquement, nomme le provincialisme et qui consiste à abandonner son caractère culturel propre, en l'aliénant à des cultures étrangères. C'est un phénomène typique d'adhésion volontaire à un statut de colonisé qui se caractérise, sinon entièrement, du moins en partie, par une incapacité à réfléchir et à approfondir son espace culturel propre, associée à une attirance envers tout ce qui lui est extrinsèque. En rapportant le texte lamentable de Glauber Rocha à son film, nous pouvons affirmer en toute certitude qu'il n'est pas un cinéaste de l'intégration du théâtre au cinéma (comme Rivette), ni de la poésie entendue comme prophétie (à l'instar de Garrel), ni de la musique (comme Straub), ni de la peinture (comme Bertolucci), ni de la politique (comme Kramer), ni du cinéma (comme Godard), excusez le schématisme de ce type de catalogage; son film, à force de vouloir être tant de choses, finit par n'être rien du tout; il finit, surtout, par n'être même plus un film (comme les autres). Il est clair 
que, comme il fallait s'y attendre, Glauber n'est pas non plus un révolutionnaire du Tiers-Monde (comme Guevara), car dans le langage qu'il prêche (le cinéma), les signes contenant les transformations nécessaires à sa pratique n'opèrent pas.

\section{Katzelmacher ${ }^{3}$}

La première surprise agréable nous est arrivée d'Allemagne fédérale, avec le film d'un jeune de 22 ans (Rainer-Werner Fassbinder) s'agit d'un excès de production peu courant (la qualité est, selon ce qui se dit, un tant soit peu inégale), nous avons trouvé digne d'intérêt de retranscrire son curriculum: en 1968, il met en scène et interprète avec son groupe "Antitheater» Katzelmacher dans un spectacle qui incluait aussi Krankbeit der Jugend de Brückner, adapté et mis en scène par Jean-Marie Straub; il interprète le rôle du bandit dans le court métrage de Straub Der Bräutigam, die Komödiantin und der Zubälter. Il débute son activité cinématographique en réalisant quelques courts métrages. En 1969, il réalise les longs métrages suivants : Liebe is kälter als der Tod; Katzelmacher; Die Götter der Pest, Warum läuft Herr R. Amok? et Rio des Mortes. En 1970 sont déjà achevés deux autres longs métrages qui n’ont pas encore été montrés au public.

«En prenant comme point de départ l'idée de Godard de produire des films aussi rapidement et au prix le plus bas possible, nous avons réalisé ce film selon les principes de l'‘ Antitheater ': tous les collaborateurs participent aux gains, aussi bien qu'aux risques, étant producteurs associés.

De nombreuses entreprises ont accepté les projets et ont soutenu notre travail par des prêts. Après la vente des premiers films, ce modèle doit s'étendre à la production et à la distribution.

Une société juridique a été fondée: la X-film, S.a.r.l et Cie. Avec Thomas Schamoni.»

Sous la bannière du Groupe de Oberhausen (Kluge, Schlöndorff, Reitz), nous avons vu à la cinémathèque nationale une partie du Nouveau Cinéma allemand, et il ne valait rien. Mis à part les cinéastes les plus intéressants de la dernière génération (Straub, Herzog, Schroeter, Fleischmann) comme d'habitude, sans prétendre en saisir les raisons.

Quelle est l'importance exacte de Fassbinder dans le cinéma allemand actuel? N'ayant pas la réponse à la question (qui d'ailleurs ne m'intéresse pas outre mesure), je commencerai par dire (et je fais bien) que Katzelmacher me paraît être un film encore sensiblement dominé par deux grandes (bonnes) influences: Garrel (de Marie pour mémoire) d'un côté et Jean-Marie Straub de l'autre.

Où finissent ces influences et où pressent-on l'apparition 4 d'une personnalité exceptionnellement douée, voilà une autre question qui, par manque de références plus précises (j’ai toujours dit que je devrais voyager davantage), me laisse un tant soit peu perplexe. Ces sombres réserves écartées (la tache tombe toujours sur le meilleur tissu), que le temps confirmera ou non, passons au film.

La première caractéristique de Katzelmacher est le refus intégral de tous les alibis réalistes, de toute volonté de s'apparenter à la réalité. Je veux dire par là que le film est structuré à tous les niveaux comme l'objet factice d'une fiction qui est présentée en tant que telle, de manière brechtienne, au spectateur. 
L'espace est neutre (les décors sont dénudés : un mur, une rue déserte dans un quartier résidentiel sans histoire, un parc avec des arbres, un banc, un ruisseau, des lits, des tables, des chaises dans des chambres dont on ne voit que la paroi du fond nue, parfois une fenêtre, des portes, des personnages inexpressifs, extatiques, avec une fonction presque exclusivement instrumentale, dans la manière de débiter le texte ou de rehausser précipitamment un geste); et il n'existe que dans une relation parallèle et frontale à la caméra, en obéissant à une stylisation extrême. Fassbinder fait alterner plusieurs scènes dans le même espace, en effectuant des variations minimes, sans jamais modifier l'axe de la caméra: il ouvre ou restreint le champ, selon l'augmentation ou la diminution du nombre de personnages dans le champ et c'est tout, et juste ce qu'il faut, avec une qualité lumineuse qui rappelle parfois Murnau.

Je pense qu'avec ce type de construction rigoureusement géométrique et délibérément théâtrale Fassbinder est parvenu à une analyse suffisamment juste de certains «symptômes » sociaux de l'Allemagne d'aujourd'hui : ses petits bourgeois stéréotypés, embourbés dans leurs affaires quotidiennes, apparemment uniquement concernés par la consom-

5 Bonacheirão est un néologisme formé par l'adjonction de cheirar bem ("sentir bon") et d'un suffixe péjoratif.

L'allusion à un «fascisme latent» me parait trop évidente pour ne pas insister sur ce point.

Ou comment les preuves réelles de la fiction se transforment en preuves de documentaire réel, comme nous nous sommes attaché à le démontrer.

\section{Détruire dit-elle}

Sur le film de Marguerite Duras, projeté à Lisbonne pendant la Semaine du Nouveau Cinéma Français, qu'on lise l'article d'Eduardo Prado Coelho publié dans ce même supplément. De prose cinématographique dite lusitanienne, n'en lisez plus un mot car, comme disait Jorge de Sena, "la stupidité humaine est grande, et sa bonté n'est pas remarquable». (Voyez Diario de Lisboa.)

Je trouve effectivement que c'est un film extrêmement intéressant mais qui, d'un point de vue personnel, ne m'intéresse pourtant pas beaucoup, si ce n'est pour renouer justement avec une notion d'«(in)supportable» que je réserve pour la conclusion. Bibliographie à l'usage des intéressés :

- Entretien avec Marguerite Duras dirigé par Jacques Rivette et Jean Narboni (Cabiers $d u$ Cinéma, no 217, novembre 1969, pp. 45-59);

- «Un Film» par Michel Delahaye (Cahiers du Cinéma, no 219, avril 1970, pp. 60-61);

- Débat avec Philippe Sollers (Le Nouvel Observateur, 05.01.1970);

- «Dans la nuit de Marguerite Duras» par Christian Zimmer (Les Temps Modernes, vol. 26, $\mathrm{n}^{\circ}$ 1, pp. 1304-1313);

- «Détruire», par Maurice Blanchot (L’Ephémère, n 13, printemps 1970, pp. 22-26). 


\section{Le jouet criminel}

Adolfo G. Arrieta est né à Madrid en 1942. Peintre de 1958 à 1964.

1964-1966: El Crimen de la Pirindola. Production, photographie, scénario, montage et réalisation: Adolfo Arrieta. N/B, 16mm, 25 min. Musique: Scarlatti. Interprétation: Xavier Grandes.

1967: La Imitacion del Angel. Prod., phot., scén., mont. et réal. : Adolfo Arrieta. N/B, 16mm, 25 min. Mus. : Messiaen, Vivaldi, Telemann. Int. : Xavier Grandes, German Portillo, Fernando Mora.

1969 : Le jouet criminel. Prod., phot., scén., mont. et réal. : Adolfo Arrieta. N/B, 16mm, 77 min. Mus.: Gustav Mahler. Int.: Jean Marais, Michèle Moretti, Xavier Grandes, Florence Delay, Philippe Bruno, J.H. Tisson, Sylvain Godet.

Voilà la courte biofilmographie (sans couleur et sans $35 \mathrm{~mm}$ ) du plus grand cinéaste espagnol, après Buñuel, et, sans doute, un des plus fins cinéastes contemporains. Il est bon de pouvoir l'affirmer, au moment précis où la cabale nous assène cet officiel attardé et nauséabond des cours d'Espagne, nommément Carlos Saura. Il est bon de pouvoir l'affirmer à tout moment, car en tout temps Adolfo Arrieta «is one of ours", pour recourir à l'expression aristocratique de Conrad qui revêt le sens qu'on veut bien lui donner, mais qui permet d'éviter certaines confusions. C'est de vies dont il s'agit!

Avant toute chose, Le jouet criminel est un film profondément politique. Disons politique en profondeur, bien que pour cette même raison son immédiateté (ou son urgence, si vous préférez) ne se révèle pas au client qui va au cinéma en espérant que le cinéma reproduise incessamment ses désirs ou son savoir, ou encore, et surtout, sa connaissance de lui-même. Aller au cinéma pour se regarder, pour regarder les siens est laid! N'y allez pas!

Arrieta a compris que (et nous ne pouvons que lui donner raison) le caractère authentiquement et légitimement politique d'un film n'est pas lié à l'événement filmé, mais à l'écriture entendue comme un travail susceptible de faire surgir cette relation. En ce sens, le film confère une autonomie à chaque plan tout en mettant en jeu une dynamique où chaque plan contredit le plan précédent, jusqu'à une accumulation de contradictions qui n'a d'autre fin que de renvoyer au matériau du film lui-même. Comme nous pouvons le voir, et c'est là que je voulais en venir, nous avons affaire à un travail complexe de montage qui se situe en premier lieu, d'un point de vue historique et critique, du côté de Cocteau, pour procéder en second lieu à la démystification et à la destruction de ce cinéma "onirique», entendu au sens de l'évasion petite-bourgeoise. Le travail cinématographique du film contredit l'idéologie de la reconnaissance en refusant au spectateur toutes les voies d'identification possibles avec l'objet filmique.

L'opacité du film? Cela s'appelle l'aurore6.

6 II s'agit là du titre d'un film de Luis Buñuel.

De manière exemplaire, Arrieta construit un sens, ensuite le détruit; il articule un travail critique en se donnant un matériau historique précis (celui de Cocteau); en somme, il s'inscrit dans le domaine matérialiste des investigations sémiotiques.

Discrètement, comme il le faut, avec quelques sous pour acheter de la pellicule $16 \mathrm{~mm}$ en noir et blanc. Et le reste, bien entendu... 


\section{Ice}

Etant donnée l'ampleur que prend cette chronique, l'appréciation du remarquable film de Robert Kramer a été différée à la chronique suivante.

\section{Pesaro 70/3.}

Robert Kramer a 29 ans. Il fait partie de la new left nord-américaine. Il a écrit deux romans (inédits) et a débuté son activité cinématographique en tournant un petit film en $8 \mathrm{~mm}$. Il a réalisé $I n$ the Country (1966), The Edge (1967), en 16mm et en noir et blanc, et Ice (1969), également en $16 \mathrm{~mm}$ et en noir et blanc, d'une durée de 135 minutes.

En décembre 1967, il encourage la fondation d'un groupe de cinéastes militants, "The Newsreel», qui tournent des courts et moyens métrages politiquement engagés. En 1968, il travaille à la préparation et au scénario de From Start to Finish, réalisé par Robert Machover qui a été l'opérateur de tous ses films.

La proposition de modernité du cinéma d'un Jacques Rivette paraît avoir trouvé un écho dans la compréhension qu'en tire Robert Kramer. Il s'agit, effectivement, de cinéastes qui portent à leur plus haut point l'exercice de la critique et l'intelligence du discours, et dont les films constituent avant tout des étapes exemplaires de réflexion ou, par excès, de révision.

De Ice, que je n'ai pu voir qu'une seule fois, je m'approche avec précaution en considérant que la lecture que j'en fais est forcément défectueuse, insuffisante et incertaine; je m'en excuse par avance auprès des lecteurs plus avertis.

Ice se veut un film de fiction politique, ce qu'il est indéniablement. Comment se structure cette fiction qui, en elle-même, se construit et se détruit, s'ouvre et se ferme, (re)produisant dialectiquement de nouvelles fictions dans/hors de sa propre narrativité?

$\mathrm{Au}$ départ, Kramer recourt d'une part à certaines «techniques» du cinéma direct (caméra $16 \mathrm{~mm}$, son synchrone) et adopte un style proche du reportage (événement filmé tiré de l'événement vécu), ainsi qu'à certaines «techniques» graphiques des ciné-tracts (légendes et photographies avec de l'information politique locale); il convoque d'autre part la représentation (théâtrale) d'une action politique révolutionnaire, interprétée par un groupe d'acteurs (anonymes), qui prend place dans un futur possible, "dans trois ou vingt ans peut-être », aux Etats-Unis.

La manipulation méticuleuse de ces éléments apparemment contradictoires et interprétés de manière contradictoire dilue l'«impression de réalité» du reportage jusqu’à produire un effet de pure "irréalité» (ou de "surréalité» extrême dans la scène du film dans le film); dans le même temps, la «théâtralité» se démasque en se dédoublant et procède à la restitution "réaliste» d'un concret véritable, au sens exact de Brecht, à travers la parole. Une parole qui est dénuée de toute obsession rhétorique ou métaphorique et qui est utilisée uniquement en tant qu'instrument de réflexion (le mot récité) ou d'action (la parole écrite).

Cinéma dans lequel le mot totalise et détermine avec une visée militante le discours filmique, en obéissant à l'analyse concrète d'une situation donnée.

Le film de Kramer constitue donc une analyse concrète de la castration des «rêves» révolu- 
tionnaires dans la société étasunienne d'aujourd'hui, ou "d'ici à trois ou vingt ans peut-être».

Peut-être qu'à cet extraordinaire cinéaste co(a)gitateur d'utopies, la célèbre phrase de Novalis peut éventuellement être appliquée: "Quand nous rêvons que nous rêvons, le réveil est proche».

\section{Pesaro 70/Conclusion}

L'activité de Garrel, en tant que cinéaste, n'est possible que parce qu'il recourt à une vieille forme de servitude intellectuelle, c'est-à-dire le mécénat. Moi aussi je prendrai congé de vous (de ces messieurs avant ces dames) car où j'irai vous ne pourrez me suivre. Ceci dit (délibérément et inexpugnablement), venons-en à notre propos.

En s'opposant radicalement («je suis absolument contre la culture») aux modes de pensée de l'establishment, à la façon de penser du spectateur, Garrel s'installe, à leur encontre, dans la logique du fantasme. Cette position peut être considérée comme doublement idéaliste, dans son fondement et dans la relation que le cinéaste prétend établir avec le spectateur: une relation de pure fascination, de silence imposé à la réflexion: "Au cinéma, à travers le film, on endort le spectateur pour un certain temps, l'obligeant à se référer à sa propre vie et, à la sortie, à se redéfinir».

De quoi nous parlent Marie pour mémoire ou Le révélateur, La concentration, Le lit de la vierge? Il s'agit de variations sur le même acte d'accusation dirigé contre toutes les formes d'ordre, de répression, d'autorité, quel que soit le visage de toutes ces formes de domination actuelles dans notre société et dans notre présent, ou encore au cours de l'histoire, représentées par les figures interchangeables jusqu'à l'infini de la loi, du père, de la famille, des règles sociales, de l'école, de l'éducation, de la psychanalyse et enfin de la religion, du christianisme et du verbe divin.

Cette dénonciation s'inscrit dans les films de manière obsessionnelle: angoisses, masochisme ou sexualité honteuse, névroses, idées fixes animent et tourmentent les personnages qui s'y meuvent. Mais ce serait se méprendre que d'attribuer à l'auteur un mécanisme de transfert de ses fantasmes sur les personnages qui les véhiculent. L'inconscient informe la structure et le langage du film, sans doute, mais en formalisant et en alternant ces fantaisies qui, avant d'être de simples "choses dites", constituent l'écriture exigeante des films, dans une tessiture de cris, de silences, de répétitions jusqu'à atteindre l'insoutenable.

Marie pour mémoire ("Un jeune homme franchit à cause d'une jeune femme le pas qui le séparait de la folie. Le film narre les mésaventures d'un psychopathe dans une société d'aliénés») établit déjà le champ des procédés garreliens: plans longuissimes, à la limite du supportable qui atteignent, une fois cette limite franchie, une violence provocatrice. Les plans sont fixes, insistants, réceptacles et révélateurs de comportements; ils accordent leurs brusques changements à des gestes brutaux, à des explosions inespérées soumises à des alternances de tensions et de dissensions.

Après l'identification obsessionnelle de Marie pour mémoire, film imprégné par la question qui l'ouvre ("Et toi, qui es-tu?») et dans lequel les interrogatoires alternent entre autodéfinition et autoproclamation, Le révélateur ( Un homme, une femme et un enfant. La révélation onirique, la cristallisation de la mémoire comme forme possible d'objectivation de la réalité freudienne. Un enfant catalyse ses réalisations odipiennes au moyen d'un hallucinogène chimique qui pour 
l'imaginaire équivaut au révélateur de la pellicule et qui jette une lumière neutre sur la formation fantasmatique de toutes les reproductions mentales») exclut la parole pour suivre des parcours topographiques tortueux et circulaires. Une famille fondamentale, primaire - matrice et moteur de toutes les relations psychologiques et sociales, de toutes les formes de censure et de répression (le film s'intitulait à l'origine Moïse ou les forces de l'ordre). Le film évolue à travers les "scènes pathologiques du rêve», marais, trous, blockhaus, cratères des cataclysmes passés et récents.

Les travellings extrêmement longs, complexes, sinueux ou rectilignes composent un défilé obsessionnel à travers des lieux désolés où nous assistons à la fuite de la famille. Il ne serait peutêtre pas hors de propos de mentionner un phénomène de judaïcité comme présence absolue dans l'intégralité de l'œuvre de Garrel. Nous sommes, éventuellement, les spectateurs d'une guerre, mais en quel lieu prend-elle place exactement, de quelle manière, et contre quels adversaires?

La concentration simplifie encore ce caractère obsessionnel et claustrophobe, en le concentrant précisément jusqu’à sa quintessence: les forces répressives ne sont pas présentes, pas même à titre de supposition, mais se situent dans un espace off, hors du film, où doivent se passer des choses encore plus horribles que celles qui se succèdent dans le film. Le fils représente l'absence autour de laquelle se nouent et se déplacent les relations entre Zouzou et Léaud réduits avant tout à des sexes, en tant qu'enfants et géniteurs simultanément. Suite à cette réduction à l'échelle originaire, selon des modules primitifs, il se produit une multiplication des sens, une abondance de symboles. C'est à partir de ces signes élémentaires, réduits aux termes essentiels d'un cinéma brut (et brutal) que se libèrent toutes les associations.

Deux acteurs, une scène unique (théâtralement construite) sujette à différentes transformations, un grand lit blanc plus ou moins carré au pied duquel nous reconnaissons une espèce de balcon ou la rampe d'une avant-scène (qu'un rideau peut cacher). De part et d'autre de ce lit, deux compartiments : l'un à gauche de l'«écran", une espèce de salle de bain (ou d'hôpital, de morgue) revêtue de carrelage blanc, où l'unique objet est un robinet d'où coule un liquide couleur de sang (du sang?); l'autre à droite, une espèce de four crématoire avec des parois de briques rouges, où brûle une flamme.

Dans cet espace la caméra fonctionne comme "un vase communicant» qui établit le lien entre les deux zones, chaude et froide.

Entre le décor et les deux personnages se crée un mouvement de va-et-vient, entre l'espace comprimé et l'espace plus ample, indéterminé et surdéterminé, entre le langage et son refus. Le décor est non seulement morgue, enfer, hôpital psychiatrique, laboratoire, mais aussi décor préfabriqué : il est possible de dire que "la scène se déroule dans un film». La dépendance envers les moyens du cinéma est continuellement signalée: les fils de microphones deviennent des cordons ombilicaux, la pellicule devient une lame qui coupe les veines, les rails et le chariot sont utilisés par Zouzou qui se traîne sur eux et dont le cadavre est transporté par ceux-ci.

En même temps, le décor conditionne le film, devient film, et le film épuise toutes ses possibilités, l'habite jusqu'à l'inhabitable. La mécanique de la saturation naît de l'abolition de toute transition entre le physique et la métaphysique.

Dans ce sens, Le lit de la vierge arrive même à mettre en doute les origines du christianisme, de la religion, du verbe divin. Ce dernier film, en tant que synthèse provisoire et retour aux 
sources, représente la somme des recherches des films précédents et une ouverture à une forme «épique».

Ce n'est pas tant le caractère farouchement idéologique des films qui est surprenant, que la manière dont Garrel théorise progressivement l'idéologie en termes filmiques ; l'implication et la cohérence de son discours, phénomène de culture, sinon culturel, aborde de manière intuitive un certain nombre de problèmes qui mettent en crise le cinéma.

Le cinéma n'est pas un simple et fidèle reflet du monde, d'une situation historique, d'une société dont il serait condamné à donner une image ou une reproduction. Il est bien plutôt un effet et un produit de la réalité. Les films de Garrel détruisent cette conception erronée, n'autorisant pas le confort d'une traduction littérale, qui est l'apanage des images (et des sons) stéréotypés du cinéma à usage bourgeois. Il ne suffit pas de psychanalyser ou d'interpréter les films de Garrel comme une simple création psychique d'un "malade mental», plus ou moins enclin à perturber notre (mais est-elle nôtre ?) tranquillité de petits spectateurs. Il en est du cinéma comme de la vie, si vous me permettez cette hardiesse.

Les films de Garrel sont plutôt un témoignage sur la condition spirituelle d'une génération en révolte; émanation, manifestation, représentation appliquée de cette génération qui est la sienne et qui peut-être n'est plus la vôtre, celle de ceux qui ont toujours été vieux, même quand ils avaient 20 ans, et qui n'est pas la mienne, après tout.

L'exemple de la très banale interpellation du public, preuve par trois du Cinéma Nouvellissime, indique bien comment Garrel peut faire jouer à sa faveur des présupposés douteux. Il est devenu d'usage courant de rompre l'«effet de réalité» sur le spectateur en recourant à un procédé selon lequel il faut, grosso modo, inscrire le travail du film dans la fiction, dénoncer le mensonge que le film représente: on montre la caméra à un moment donné du film, on s'adresse au public (ce peut être le réalisateur, ou un substitut, ou qui de droit) pour le contraindre à prendre conscience, ou pour l'insulter, ou pour demander l'aumône, etc. Il est évident que ce processus ne suffit pas à ce qu'un film ait un caractère matérialiste en lui-même. Il arrive même que, chez Garrel, au lieu de briser la fascination du film, ce processus vient au contraire la renforcer et la confirmer en individualisant à travers son caractère halluciné et hallucinatoire le champ du film : La concentration ou cette réplique de Didier Léon dans Marie pour mémoire:

«Interrompez la projection si je me trompe, ce qui m'inspire est mon intuition qui précède la raison. Je reviens pour vous apprendre que désormais le temps et l'espace ne moppriment plus. Pour cette raison, mon âme est un ciel ouvert! L'homme a créé Dieu à l'image de sa propre créature, sa conduite répressive aggrave son état de privation. Pour se libérer, pour retrouver la mémoire, pour s'empêtrer dans toutes les métaphores qui le perturbent. Un dernier mot, encore : l'état dans lequel je précipite les propos de l'homme inconscient qui m'habite s'appelle... folie.»

La provocation, comme dans le terrible "Mon enfant!» de Marie pour mémoire ou dans la bande sonore excessivement stridente de La concentration, ne constitue pas une simple agression physiologique: la négation violente et totale ne participe pas à une intention de discontinuité, mais à une vision synthétique. La propre écriture du film a un caractère physique et se développe à l'intérieur de l'espace du film: non pas dans un espace préexistant que le film devrait découvrir 
en le soumettant à ses lois, mais dans un espace, un mot, des gestes que l'écriture détermine et organise, en même temps qu'elle se détermine et s'organise elle-même. Ceci dit, le film ne fait rien de plus qu'affirmer en permanence la fonction dangereuse du cinéma et, à partir du moment où son statut pathologique est reconnu, affirmer le cinéma comme un mode malsain d'assumer des relations sociales.

Mais ce propos, loin de constituer le projet préexistant du film, ne se dégage qu'à travers le travail du film, pour atteindre à l'illumination, la clairvoyance et la justesse.

«Le film est l'enfant que je ne fais pas. Et c'est pour cela même que je trouve que le cinéma a quelque chose de monstrueux", disait Garrel; et moi, un pied ici

7 Não ato nem desato signifie littéralement "je ne noue ni ne dénoue", équivalant en français à "je n'en démords pas". et un autre là-bas 7 , je songe en me mettant à sa place, dans sa tête, que «ce saut dans le vide n'a de comptes à rendre à personne»...

\begin{abstract}
Texte paru exactement un mois
une revue spécialisée dédiée au cinéma. Dans le climat d'instabilité politique dans laquelle se trouvait le Portugal à ce moment-là, ce texte marque la fin d'une période pour Monteiro; en effet, il ne publiera dorénavant plus d'écrits de critique de cinéma et s'engagera entièrement dans la production de films. Toutefois, sa position de réalisateur ne l'empêchera pas de faire des incursions tonitruantes et incisives à plusieurs reprises dans la sphère publique.
\end{abstract}

1Titre original: Pequeno papelinho qui peut tout aussi bien signifier "petit papier" que "petit rôle".

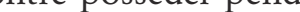
sion asphyxiante: deux doigts d'imagination, une pincée d'intelligence, un rien de subtilité et de délire, un soupçon de rigueur poétique.

Aux autres, et spécialement à Antonio Reis, pour tout ce qu'il représente en tant que cinéaste et citoyen, je souhaite également que dorénavant ils puissent trouver des conditions moins brutales pour une pratique cinématographique régulière et chaque fois plus orientée dans le sens d'une extrême et déjà pressentie exigence. Quant à moi, je suis un homme malade, un cas précoce de domestication. Quand, il y a des mois, j'ai offert mes services pour faire partie de la rédaction de cette revue (et faut-il le dire, j'ai entretenu avec tous mes collègues et supérieurs hiérarchiques les relations cordiales et amicales les plus pures), mes inclinations étaient, si je ne me trompe pas, et je ne crois pas me tromper, bien claires : engraisser et écouter de la musique. Le cinéma, loin des yeux. Cela me maintient le port altier, bien qu'en ce qui concerne la graisse j'ai 
échoué lamentablement. Tout indique que cette hautissime vocation m'est pour toujours interdite. J'essaierai (quelle sinécure!) de revenir à la lutte pour faire des films avec le peu dont je suis fait.

Il faut aiguiser le plus tôt possible la dent cinématographique pour que le cinéma soit capable de triturer, digérer et chier la réalité. Ainsi seulement il aura une fonction de transformation. Si le cinéma ne court pas plus vite que la réalité, il court le risque de la saisir comme un pâle reflet. Je suis profondément convaincu, malheureusement, que ce cinéma néo-parasitaire sera le cinéma dominant de la société portugaise, comme il l'a toujours été, d'ailleurs, ici et partout ailleurs.

Mon drame est que j’ai été déclaré inapte au service militaire et je ne sais pas très bien si, en toute discipline, je dois me mettre derrière ou devant les canons. Quelques types de la politique m'ont déjà expliqué que c'est selon: toujours derrière dans la métropole, toujours devant dans les colonies. Face à cette opinion contradictoire je crois que je vais me tenir recroquevillé, c'est ce que j'ai toujours fait et que je continuerai à faire. La seule différence est que maintenant je connais (mal) des types qui se sont démarqués pour des postes de direction et qui me paraissaient curieusement déjà plein de vermine et bien nourris sous l'ancien régime. Il faudra que je coupe les liens rapidement avec ces gens qui à travers des formes plus nocives et raffinées se préparent à continuer à sucer les pauvres peaux des crève-la-faim de ce pays. Je crois pieusement à la dialectique de la dévoration et à l'impossibilité de construire un pays habitable tant qu'il y aura des personnes qui mangent et d'autres personnes qui sont mangées. En y pensant mieux, cette enquête ne fait pas sens:

LE CINÉMA C'EST MOI, c'est-à-dire : la création est absolue et absolument inconfortable.

JOURNAL INTIME DE JEAN DE DIEU - Publié en 1999 sous le nom: Une semaine dans une autre ville (éditions \&etc), avec le journal intime que João Cé-

Lundi 8 Juillet

Les culottes de la fille de $\mathrm{M}^{\mathrm{me}}$ Ascension ont disparu de la corde à linge.

Mardi 9 juillet

Mercredi 10 juillet

Jeudi 11 juillet

Vendredi 12 juillet
J'ai encore oublié d'acheter un vase pour planter quelques pieds de persil.

Il y a des jours où un homme ne peut pas sortir de chez lui.

L'obstination de Stavroguine m'échappe quand, entre quatre yeux, il assure à Chatov n'avoir jamais abusé d'enfants.

Le tremblement de terre de 1755 ne suffit pas à expliquer cette rumeur mystérieuse du soir.

Abyssus abyssum invocat... sar Monteiro a tenu lors d'un voyage à Paris, tandis qu'il cherchait à adapter à l'écran La philosophie dans le boudoir du marquis de Sade. Paru sans autre indication de provenance, ces brèves notes, fragmentaires, se situent vraisemblablement dans le sillage du premier volet de la trilogie, Souvenirs de la maison jaune.

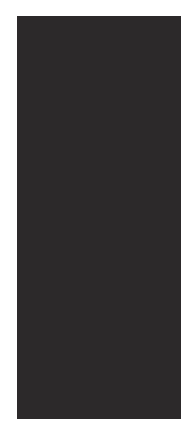


Samedi 13 juillet

1 Jeu de mots intraduisible sur les mots aziago ("funeste") et azia ("aigreur d'estomac").
J'ai passé cette funeste journée sans aigreur d'estomac ${ }^{1}$. Bénis soient les épinoches avec un riz aux poivrons.

Branlette? Soit, donc.

A propos: Les culottes de la fille de $\mathrm{M}^{\mathrm{me}}$ Ascension sont réapparues au milieu d'un tas de déchets. L'honneur du couvent est sauf.

Première scène de la première version du scénario du Bassin de J. W. ; cette - MUSÉE DU CINÉMA. INTÉRIEUR, JOUR scène n'a pas été retenue au montage.

Jean de Dieu est guide dans le Musée du Cinéma à Paris.

La visite qui nous amène ici commence exactement dans le coin où, à côté de la Jeanne d'Arc de Dreyer, se trouve la Créature Machinale de Walter SchulzeMitendorff conçue à partir du corps moulé de Brigitte Helm pour le Metropolis de Fritz Lang.

- C'est un illustre ancêtre de Star Wars de Lucas - explique Jean de Dieu au groupe de visiteurs, en lançant en coin un regard complice et furtif aux genoux fermés de Falconetti qui grimpe les escaliers qui la metteront en présence des juges, dans la salle du tribunal.

- On a la sensation que le corps de l'actrice habite encore l'intérieur de la structure métallisée. Comme si le revêtement argenté était à peine un prétexte pour le rendre inexpugnable à notre regard - observe une visiteuse plus curieuse.

- C'est peut-être la différence entre un travail de sculpture et un travail de carrossier - suggère Jean de Dieu.

- Mais une sculpture profondément charnelle - insiste la visiteuse.

- Hélas, Madame - dit Jean de Dieu - probablement, nous ne sommes pas loin des Egyptiens. En fin de compte, ne serions-nous pas devant le même désir violent de soustraire les corps à la corruption charnelle pour, à travers une prodigieuse alchimie, mieux les rendre à leur véritable splendeur? Ne serait-ce pas cela le cinéma? Je voudrais attirer votre attention sur une curieuse particularité : cette Créature a une rangée de clous plantés derrière le crâne. Si vous regardez attentivement la photographie de Falconetti qui se trouve là-bas sur cette paroi, vous pourrez vérifier que cette trépanation de martyr anticipe non seulement la crémation de Jeanne d'Arc sur le bûcher, mais aussi son propre jugement.

La visite se poursuit selon une direction strictement personnelle, que nous expliquerons avec plus de précision quand le producteur du film nous permettra de faire une longue visite des lieux. Pour l'instant, il nous suffit de retenir quelques étapes du parcours :

Marey, Lumière, Méliès, Griffith, Chaplin, Stroheim, Vigo, Renoir, Rossellini, Max Ophüls, Jacques Demy...

Maintenant nous sommes devant l'entrée d'un décor du Nosferatu de Murnau. Un petit frémissement parcourt les visiteurs. 
- Selon la légende - explique Jean de Dieu - l'acteur qui interprète le rôle du vampire dans le film de Murnau (Max Schreck) serait mort deux ans avant le début du tournage, ce qui revient à dire qu'il s'agissait d'un véritable vampire.

A ce moment, du fond du décor surgit une figure livide et chancelante, qui porte un blouson bleu marine. Il s'agit d'un marin portugais nommé Henri, mais au vu de la surprise de l'apparition et des ressemblances physiques avec le fameux comte, la frayeur est compréhensible.

- Mon Dieu, mon Dieu, que faites-vous là? - demande Jean de Dieu à l'inconnu, tandis qu'il fait machinalement le signe de croix.

- Je cherche John Wayne - s'enquiert calmement et avec une voix humaine l'inconnu.

- Et vous pensiez le trouver ici? Qui plus est, les visiteurs ne peuvent pas s'installer dans les décors du musée. C’est strictement interdit.

- Je sais, Monsieur. Il en va de même partout, mais j'étais extrêmement fatigué et je me suis endormi, là-bas au fond, dans ce coin sombre. Je vous demande pardon.

- Mais ce que vous dites est inconcevable. Ceci n'est pas un dortoir. Et pourquoi pas dans le lit de Lola Montes?

- Le lit de Lola Montes n'est pas très propre.

- Comment ça, il n'est pas très propre?

- Il y a des vers. Pour cette raison j’ai préféré changer de lieu.

- Quoi? Alors à ce que je vois, il ne s'agissait pas d'une somnolence occasionnelle. Monsieur, outre le blasphème, vous êtes un récidiviste chronique, un vieux vicieux, et je suis forcé de vous conseiller de quitter immédiatement les lieux, en espérant que vous m'épargnerez le désagrément d'appeler les forces de l'ordre.

- Sans avoir vu John Wayne?

- Pour voir John Wayne, mon cher Monsieur, il faut le mériter. Je doute que, au vu de votre comportement, vous ne possédiez le prérequis minimum pour que cette rencontre ne soit pas un pur sacrilège.

- Je viens de très loin pour voir John Wayne. De Lisbonne, si vous voulez le savoir.

- J'ai entendu dire que c'est une ville enchanteresse, la ville blanche.

- Blanche, mon $\mathrm{cul}^{2}$.

2 En français dans le texte.

- Bon! Je vais vous montrer John Wayne, mais après vous déguerpissez. D’accord?

- D’accord. Monsieur est très gentil. Et excusez-moi pour tout à l'heure. Ce sont des vertiges...

- Des vertiges? Ça doit être le fait d'une basse tension. Bon! Allons voir Wayne et n'en parlons plus.

Jean de Dieu, suivi par Henri et par le groupe de visiteurs, se déplace jusqu'à un tirage photographique de John Wayne qui, par les bons soins de Ford, chevauche dans The Searchers. Ils admirent en silence la photographie. Henri se retourne vers le groupe et s'exclame:

- C'est bien ce que je pensais. Je peux partir l'esprit tranquille.

Henri regarde la photographie une dernière fois, prend congé avec un léger mouvement de la tête et s'éloigne. Jean de Dieu accourt derrière lui. 
- La sortie n'est pas par là. C'est dans l'autre direction.

- Je n'ai pas de boussole sur moi - s'excuse Henri.

- Par simple curiosité, connaissez-vous le film d'où la photographie a été tirée? - demande Jean de Dieu.

- Bien sûr.

- C'est un très beau film. Vous aimez?

- J'adore. C'est mon préféré.

- Je pleure comme une madeleine chaque fois que je le revois - dit Henri, mimant le geste de Wayne qui soulève sa nièce dans ses bras.

Ah! Un étonnement après l'autre.

- John Wayne était mon idole quand j'étais jeune. J'ai grandi avec lui et nous avons traversé beaucoup de choses ensemble. On ne crée plus des acteurs de cette trempe.

- Vous avez peut-être raison, mais qu'est-ce qui en lui vous fascine d'une manière aussi véhémente, si je puis dire?

- Je ne sais pas. Tout.

- Je voudrais savoir si c'est le corps, la voix, le caractère, le charisme...

- C’était la cible privilégiée de tout le monde...

- Des peaux-rouges peut-être, je ne dis pas, mais je ne crois pas que ce soit son trait le plus caractéristique. Je pense que fondamentalement, il est le guerrier de toutes les guerres, le Dieu Mars de l'Olympe cinématographique.

- Moi, en cinéma, je n'y connais rien, mais je pense que vous êtes dans le faux. De mon point de vue, il est la cible privilégiée de tout le monde, le bouc-émissaire qu'il faut éliminer à tout prix. La guerre en est une conséquence, une provocation qui lui est imposée en permanence. Et maintenant, si vous permettez, je dois partir. J'ai vu ce que j'avais à voir.

- Si vous me donnez votre parole d'honneur que votre comportement sera dorénavant, disons-le ainsi, un peu moins étrange, je vous permets de poursuivre votre visite. Les institutions ont leurs règles, mais n'allons pas faire le jeu d'un dogmatisme intolérable et aveugle. Après tout, vous avez acheté un billet, non?

- Je vous en remercie infiniment, mais j'ai encore quelques visites à faire. Une autre fois, j'aurai beaucoup de plaisir à ce que vous me montriez votre musée.

- Dans ce cas, je vous raccompagne jusqu'à la sortie.

- Ne vous dérangez pas pour moi.

- Cela ne me dérange nullement. Les autres auront de quoi s'entretenir sur le chemin.

Jean de Dieu accompagne Henri jusqu'à la sortie.

- Si vous avez besoin de quoi que ce soit dans cette maison, n’hésitez pas. Jean de Dieu est mon nom.

- Henri. Un vieux loup de mer à la retraite, à votre service.

- Henri, le navigateur.

- Portugais et détrompé.

- Ne dites pas ça. J'ai beaucoup aimé notre conversation sur John Wayne. On voit que vous êtes un véritable connaisseur de cinéma. Et, ici entre nous, maintenant que j’ai fait votre 
connaissance, je suis convaincu que ce n'est pas par hasard que vous avez surgi du décor de Nosferatu.

- Mais je vous jure que je ne voulais voir que John Wayne. Le voir et mourir après.

- Plus personne ne meurt ainsi. La preuve en est que vous êtes toujours vivant, et bien vivant. S'il en allait autrement, nous devrions cesser les visites guidées.

- Je n'avais pas l'intention de finir ici. Vous me prenez pour qui à finir mes jours dans un musée?

- Finir près des dieux est un privilège.

- Sornettes. Je préfère finir au pôle Nord.

- Au pôle Nord?

- J'ai rêvé que John Wayne bougeait merveilleusement du bassin au pôle Nord.

Laissant Jean de Dieu bouche bée, Henri s'éloigne rapidement dans la direction de la sortie et disparaît à l'extérieur.

Jean de Dieu se retourne dans la direction d'une photographie de Henri Langlois et lance:

- C'est de ta faute!

«Continue, chéri!», peut-on lire.

CORPS SUBMERGÉ - Recueil de poèmes paru en 1959, à compte d'auteur, alors que João Cesar Monteiro avait 20 ans. Ce dernier essaya de retirer de la circulation autant d'exemplaires qu'il lui fut possible; les seuls exemplaires encore existants proviennent de la collection privée de la poétesse Luiza Neto Jorge qui en avait acquis un certain nombre. Ce texte nous semble à même de fournir un autre éclairage sur l'œuvre de Monteiro.

\section{Personne ne m'espionnait et, illicitement, par espièglerie, j'ai profité de la préface}

"S'il est vrai que je suis poète par la grâce de Dieu - ou du Démon - c'est aussi grâce aux efforts et à la technique, et à ma conscience dans l'absolu de ce que doit être un poème.»

Federico Garcia Lorca

«... à ma conscience dans l'absolu...»!...

A quel point se hisserait ma présomption si je soutenais la même chose, aujourd'hui, en 1959 !... Je suis un apprenti poète. Pas un POÈTE, remarquez, mais en vérité, je m’adresse aux sans défense, un APPRENTI POĖTE; toutefois... je ne veux pas mourir à présent sans atteindre à la conscience absolue ou non de beaucoup d'autres choses.

\section{CORPO SUBMERSO}

Ninguém me espiava e ilicitamente aproveiteime, surrateiro, do prefácio

"Si es verdad que soy poeta por la gracia de Dios - o del demonio - también lo es que lo soy por la gracia del esfuerzo y de la técnica, y de darme cuenta en absoluto de lo que es un poema."

Federico Garcia Lorca

"... de darme cuenta en absoluto..." !...

A que ponto chegaria a minha presunção ao afirmar tal, agora, no ano de 1959 !... Sou um aprendiz de poeta. Não um POETA, reparem, mas, na verdade, e apenas dirigindo-me aos indefesos, um APRENDIZ-DE-POETA; todavia... não quero morrer agora sem ter a consciência absoluta do que é um poema. Não quero morrer 
agora sem ter a consciência absoluta ou não de muitas outras coisas. Não quero morrer agora até porque não quero com ou sem razões morrer agora.

Concluímos: Só os SUICIDAS querem morrer agora ou querem morrer antes ou depois de agora, aladamente, como que inventando um subtil-tempo-suporífero.

Não direi uma palavra sobre a minha poesia. Amanhã falaremos POESIA que nos será tão necessária quanto hoje. Disso dependerá a nossa LIBERTAÇÃO.

De mim eis o que esquemática, incompleta, mas não definitivamente será auto-dito.

Nasci há pouco menos de vinte anos à beiramar (donde esta nostalgia marinha). Nunca suportei cócegas.

Educação: Refractário a cavalo marinho como força repressiva. Inutilidade absoluta.

Brincadeiras preferidas: Atirar merda à cara das pessoas, atracção inocente pelo fogo (não chegava a ser piromania) e, por vezes, partir vidros ou objectos utilitários.

Religião: Urinismo (Mijo foi o deus da minha infância). O ritual de carácter abertamente herético consistia em Mijar em igrejas e conventos.

Primeiro desejo sexual: Satisfeito no primeiro orificio ao alcance. A masturbação surgiu mais tarde, processando-se, com uma elaboração de método mais complexo e aperfeiçoado deste primeiro impulso.

Primeiro amor: Mas uma criança do sexo feminino, naturalmente!

Primeiro poema: Vide alinea interior.

Unico facto histórico (o porquê da minha imortalidade): A BARRICADA. (Assim foi apelidado, contado e recontado e o serà de geração em geração na história da cidade à beira-mar, até à consumação dos séculos).

Causas: Oposição materna à minha visão cinematográfica de OS TAMBORES DE FU-MANCHÚ.

Consequencias: Destruição total e violenta dos vidros e da canalização da água da casa paterna. Como consequencia disto, e ameaçado com a intervenção de forças policiais, surgiu, então, a necessidade da barricada, que culminou com a rápida e eficiente entrada em cena de uma alta personalidade (anos depois Presidente da Câmara) sendo definitivamente aniquilada no exílio de um mês (para repouso e presumível tratamento) em casa de uns tios de aldeia, onde ainda decapitei com um aguçado machado uma boa meia dúzia de inofensivos cágados.
Je ne veux pas mourir à présent parce qu'avec ou sans motifs je ne veux pas mourir à présent.

Concluons: Seuls les SUICIDÉS veulent mourir à présent ou veulent mourir avant ou après cet instant, à la dérobée, comme en inventant un subtile-temps-imaginaire.

Je ne piperai mot sur ma poésie. Demain nous parlerons POÉSIE qui nous est aussi nécessaire qu'aujourd'hui. En dépendra notre LIBÉRATION.

Voici de ma personne un portrait schématique, incomplet, mais qui ne sera pas définitivement autoproclamé.

Je suis né il y a un peu moins de 20 ans au bord de la mer (d'où cette nostalgie maritime). Je n’ai jamais supporté les chatouilles.

Education: Réfractaire au fouet comme force répressive. Inutilité absolue.

Divertissements: Jeter de la merde au visage des gens, une innocente attirance pour le feu (sans en arriver à la pyromanie) et, parfois, briser des vitres ou des objets utilitaires.

Religion: Urinisme (la pisse a été le dieu de mon enfance). Un rituel de caractère ouvertement hérétique consistant à pisser dans les églises et les couvents.

Premier désir sexuel : Satisfait dans le premier orifice à ma portée. La masturbation est apparue plus tard, se pratiquant avec une élaboration de méthode plus complexe et perfectionnée à partir de cette première impulsion.

Premier amour: Mais une enfant de sexe féminin, naturellement!

Premier poème: Voyez l'alinéa ci-dessus.

Unique fait historique (la raison de mon immortalité): LA BARRICADE. (Telle qu'elle a été nommée, contée et racontée et le sera de génération en génération dans l'histoire de la ville au bord de la mer, jusqu'à la consommation des siècles).

Causes: Opposition maternelle à ma vision cinématographique des TAMBOURS DE FU-MANCHÙ.

Conséquences: Destruction totale et violente des vitres et de la canalisation de la maison paternelle. En conséquence de ce geste, et sous la menace de l'intervention des forces de l'ordre, a surgi, alors, la nécessité de la barricade, qui a culminé avec l'entrée en scène rapide et efficace d'une haute personnalité (devenu des années plus tard Président de la commune) m'anéantissant définitivement par un mois d'exil (pour le repos et traitement présumé) chez quelque oncle du village, où j’ai encore décapité avec une hache affûtée une bonne demi-douzaine de tortues d'eau. 
Ont pris part à la BARRICADE, excepté ma personne, toujours héroïque, la poitrine exposée aux fauves, dans cette chambre inoubliable avec vue sur la rue et la porte obstruée par le lit, le matelas, l'armoire, le pot de chambre (si ma mémoire ne me trahit pas), etc.: un drapeau national, deux fusils, un revolver, beaucoup de canifs, beaucoup de poules, quelques vivres et une chienne, mon lieutenant, que des ennemis prétendaient être mon amante, ce qui est absolument faux et injurieux, étant donné que nos relations n'ont jamais dépassé le plan d’une solide, saine et fraternelle amitié.

Beaucoup de gens accourus aux cris maternels, palabraient entre eux à la fenêtre, mais moi, menaçant, écumant de rage, je les ai dispersés, les assommant, un revolver à la main et un couteau entre les dents.

- Il est fou! Il est fou ! - criaient les gens en fuyant, précipitamment, prenant leurs jambes à leur cou.

\section{MAIS ÉTAIS-JE RÉELLEMENT FOU?}

J'ai résisté, comme nous l'avons dit, jusqu'à l'arrivée du Monsieur qui par après deviendrait Président de la commune, non sans lui avoir presque plongé le double canon d'un fusil dans les orbites. JE N'ÉTAIS POURTANT PAS FOU! QUE POUVAIS-JE FAIRE D'AUTRE? QUEL DOMMAGE DE NE PAS AVOIR ÉTÉ FOU!...

Mon enfance est morte cruellement. Et je suis ressuscité tel un phénix de mes cendres. Rien ne m'a été légué par l'infant décédé, enterré profondément et couvert de rochers, de rochers et de plus de rochers encore, ainsi que de chaînes gigantesques... ...La réflexion et le poids des choses font si mal.
Tomaram parte na BARRICADA além de mim, sempre heroico de peito exposto às feras, nesse imorredoiro quarto com vistas para a rua e a porta obstruida pela cama, colchão, guarda-fato, penico (se a memória não me trai), etc., uma bandeira nacional, duas espingardas, um revólver, muitas navalhas, muitas galinhas, vários mantimentos e uma cadela, o meu lugar-tenente, que inimigos meus diziam ser minha amante, o que é absolutamente falso e injurioso, dado que as nossas relações não passaram nunca de um plano de sólida, sã e fraterna amizade.

Muita gente que acorreu aos gritos maternos falava entre si junto à janela, mas eu, ameaçador, espumando raiva, dispersei-a, assomando de revólver em punho e uma navalha atravessada nos dentes.

- Está louco! Está louco! - berrava a gente fugindo, precipitada, com os tornozelos agarrados ao cu.

\section{E ESTARIA REALMENTE LOUCO?}

Resisti, como já vimos, até à chegada do senhor que mais tarde seria Presidente da Câmara, não sem, quase, Ihe ter enfiado os dois canos de uma espingarda pelos olhos dentro. NÃO ESTAVA, PORTANTO, LOUCO! QUE OUTRA COISA PODIA EU FAZER? QUE PENA NÃO TER ESTADO LOUCO!...

A minha infância morreu cruelmente. Renasci como Fénix das cinzas. Nada me foi legado pelo infante morto, que enterraram fundo e cobriram com rochedos, rochedos e mais rochedos ainda e gigantescos grilhões... ...Doi tanto a reflexão e o peso exacto das coisas.
"Comme l'amour est différent au Portugal!" "Ah! Canaille. Et le pou?"

Ou

"Comme le pou est différent au Portugal!" "Ah! Canaille. Et l'amour?"

Amour soigneux je descendais avec la somnolence d'un bœuf pacifique la rue élégante de la ville quand je t'ai vu chou-fleur de beauté exposée comme un rêve sur mes pas

\author{
"Como é diferente o amor em Portugal!" \\ "Ah! Canalha. E o piolho?" \\ "Como é diferente o piolho em Portugal!" \\ "Ah! Canalha. E o amor?"
}

Ou

Descia eu amor cuidadoso

com a sonolência dum boi pacifico

a rua elegante da cidade

quando te vi couve-flor de formosura

atravessada com um sonho em meus passos 
A tua esguia mão banhada em casto leite baloiçava pendular um chapéuzinho que em qualquer velha desdentada é similar mas não tem a mesma ternura coitadinho

Teus seios espetavam-me quase irónicos e [triunfantes

(- Que gordas bolas - gemeu até um velho [padre que passou)

Dos teus olhos desprendiam-se chamas [delirantes

que teu honrado e pançudo pai

certamente ainda não notou

Por ti amor com quem a Natureza

se quedou exausta

Por ti magna obra-prima

oculto vagido de perfeição

todo o mijo de mulher se me substituiu

por um sóbrio e viril aroma de violeta e jasmim

Por ti até de cuecas seria embaixador no Vaticano

ou no rosado e concâvo cu de teu orgulhoso pai

comeria um sujo caldo de hortaliça e feijão

Mas eis que amor pela tua grácil nuca

um piolho desce desvairado

dando voltas e voltas e mais voltas

ao teu harmonioso pescoço bem lavado

E foi então que minhas mãos

solícitas teceram desfraldadas

um nocturno novelo apaixonado

na apavorada superficie estrangulada

Tombaste na rua elegante da cidade mesmo à porta duma agência funerária Estendi-me patético a teu lado olhando o céu quase claro e velado Das nossas mãos entrançadas cabelos de sangue em torno de nós se [espalhavam

Duas velas de sebo a nossos pés lado a lado perfiladas

sentinelas ferozes pelo mau cheiro que [exalavam
Ta main efflanquée baignée dans un chaste lait balançait de part et d'autre un petit chapeau analogue pour chaque vieille édentée mais n'a pas la même tendresse le malheureux Tes seins me transperçaient presque ironiques et triomphants (- Quelles grasses boules - même un vieux prêtre qui passait a gémi) De tes yeux sortaient des flammes délirantes que ton honoré et bidonnant père n'a certainement pas encore remarquées

Pour toi amour dont la nature est tombée épuisée

Pour toi noble chef-d'œuvre occulte mugissement de perfection toute la pisse de femme m'a été substituée pour un arôme sobre et viril de violette et de jasmin Pour toi même en culotte je serai ambassadeur au Vatican ou dans le cul rosacé et concave de ton orgueilleux père je mangerai une soupe sale de légumes et de haricots

Mais voici que l'amour pour ta gracieuse nuque un pou descend étourdi faisant des tours et des tours et plus de tours autour de ton harmonieux cou bien lavé

Et c'est alors que mes mains sollicitées ont tissé dénudées une pelote nocturne passionnée sur la surface apeurée étranglée

Tu es tombée dans la rue élégante de la ville à même la porte d'une agence funéraire Je me suis étendu pathétique à tes côtés regardant le ciel presque clair et voilé De nos mains emmêlées des cheveux de sang se répandaient autour de nous Deux bougies de crasse à nos pieds profilées côte-à-côte sentinelles féroces par la mauvaise odeur qu'elles exhalaient 
Le pou défilait sur ton ventre bleu

sifflant une chanson pacifiée et remarquant que j'écoutais en silence

cria suave comme un doux pape

- Merci dégoûtant camarade ainsi horizontal et facile mon destin sera infaillible et divin.
O piolho em teu ventre azul desfilava

assobiando uma canção pacificada

e reparando em mim atónito escutava

berrou meigo como um papa meigo

- Obrigado nojento camarada

assim horizontais e fáceis

o meu destino será infalível e divino.

\section{Nocturne}

heure de chiens urinant sur la dignité des lampadaires

heure suspendue

de revolvers indécis

heure végétale de

poètes saouls

heure à laquelle avec moi

se croisent les bons yeux

de Gomes Ferreira et moi

reniflant avec envie

la femme nue qu'il

emporte dans les bras

car j'ai toujours eu

la certitude qu'il emportait

une femme nue dans les bras

à cette heure terrible

de lunes jaunes

à cette heure proposée

par l'angoisse des montres

à cette même heure annihilatrice

des consciences bourgeoises

ne pensez pas que je vais me

lancer dans le Tage

ou hurler à la lune

sur la statue

du Marquis

ou pourrir éternellement

sur les bancs de l'Avenue

\section{Nocturno}

hora de cães urinando

na dignidade dos candeeiros

hora suspensa

de revólveres indecisos

hora vegetal de

poetas bêbedos

hora em que comigo

se cruzam os olhos bons

do Gomes Ferreira e eu

farejos com cio

a mulher nua que ele

leva nos braços

porque eu tive sempre

a certeza que ele levava

uma mulher nua nos braços

nesta hora terrível

de luas amarelas

nesta hora proposta

pela angústia dos relógios

nesta mesma hora aniquiladora

de consciencias burguesas

não pensem que me vou

lançar no Tejo

ou uivar até à lua

na estátua

do Marquês

ou apodrecer eternamente

nos bancos da Avenida 
ouvindo o apito dos comboios que partem para Paris não

depois de passear pela cidade a minha jovem experiência digo jovem para não complicar vou quando nascer o dia a casa da Natália preparar-Ihe o pequeno almoço Romeu pondo torrões de açúcar no café de Julieta ressuscitar o mito dos seus làbios dançar a rumba vestido de profeta bíblico e ouvir a cantata da Paz de Sergei Prokofieff pedir-Ihe-ei então para me fazer um poema ATENÇÃO NÃO SE MEXA em que eu esteja num tapete persa com os braços erguidos ordenando ao sol que vá pelos subterrâneos e pelos caixotes de lixo inundar de luz e de amor o homem escravizado dizer-lhe que as horas passadas e presentes partiram dum mal entendido que o futuro destruirá ordenando ao sol que golpeie os bárbaros de raios e labaredas para poupar aos homens a experiência do ódio écoutant le sifflement des trains qui partent pour Paris non

après avoir promené dans la ville ma jeune expérience je dis jeune pour ne pas compliquer je vais quand le jour naîtra chez Nathalie lui préparer le petit-déjeuner Roméo mettant des morceaux de sucre dans le café de Juliette ressusciter le mythe de ses lèvres danser la rumba vêtu en prophète biblique et écouter la cantate de la Paix de Sergei Prokofieff je lui demanderai alors de m'inspirer un poème ATTENTION NE BOUGEZ PAS dans lequel je serai sur un tapis persan les bras levés commandant au soleil qu'il aille par les souterrains et par les bennes à ordures inonder de lumière et d'amour l'homme en esclavage lui dire que les heures passées et présentes surgirent d'un malentendu que le futur détruira commandant au soleil qu'il frappe les barbares de foudres et de flammes pour épargner aux hommes l'expérience de la haine 


\section{Mon amour est parti pour les colonies}

mon amour est parti pour les colonies jouer la prostituée

avec les blancs de la Compagnie du Sexe

et m'a laissé sur cette plage

regardant la mer avec envie drainer le sable pour son alcôve de silence

et la grasse lune se dénuder

entre nuages et lamentations

mon amour est parti pour les colonies

acheter un petit singe

pour l'aimer pour de vrai

quand le blanc sera saoul

couché entre les bouteilles

mon amour est parti pour les colonies

et reviendra vieille couleur de paille

sentant le savon

et les fleurs de sa chevelure

seront des squelettes de poussière

sans le parfum des jardins

elle ramènera ses économies

pour ouvrir une maison raffinée

de jeunes prostituées

paiera l'impôt de l'Etat

avec beaucoup de régularité

aura une chambre discrète

pour les gens distingués

et quand la police viendra

arrêter Lola la rousse

qui frappa le Général

ou voir s'il y a de la contrebande

mon amour ouvrira le coffre

et résoudra les difficultés

\section{0 meu amor foi p'ras colónias}

o meu amor foi p'ras colónias

foi brincar de prostituta

com os brancos da Companhia do Sexo

e deixou-me nesta praia

vendo o mar com cio arrastando areias

para a sua alcova de silêncio

e a lua gorda despindo-se

entre nuvens e lamentos

o meu amor foi p'ras colónias

foi comprar um macaquinho

para o amar de verdade

quando o branco estiver bêbedo

entre garrafas deitado

o meu amor foi p’ras colónias

e virá velho cor da palha

a cheirar a sabonete

e as flores do seu cabelo

serão esqueletos de pó

sem perfume de jardins

trará as suas economias

p'ra abrir uma casa fina

de prostitutas novinhas

pagará imposto ao Estado

com muita regularidade

terá um quarto discreto

para a gente da alta roda

e quando vier a Polícia

prender a Lola que é ruiva

e bateu no general

ou ver se há contrabando

o meu amor abre o cofre

e desfaz a complicação 
e quando vier o médico na manhã fria de olheiras com a malinha da inspecção meu amor deitar-se-á sobre penas de pavão e jurará ao doutor que todo o mundo está são

e quando eu logo me matar sairei pelas traseiras com a Santa Madalena que veio p'ra me beijar

então

desceremos pudicamente o rio ondeado de lírios como dois namorados semeando auroras ai meu amor

semeando auroras semeando auroras et quand le médecin viendra

au matin frais mal réveillé

avec la malette de l'inspection

mon amour se couchera

sur les plumes de paon

et jurera au docteur

que tout le monde est sain

et quand bientôt je me tuerai

je sortirai par derrière

avec la sainte Madeleine

venue pour m'embrasser

alors

nous descendrons pudiquement

la rivière ondoyante de muguets

comme deux amoureux

semant des aurores

ah mon amour

semant des aurores

semant des aurores 